\title{
Corruption Threats in Regulations: Analytical Review of the Literature and Case Materials of the Russian Federation
}

\author{
Valeriy A. Letyaev ${ }^{1} \&$ Ekaterina V. Letyaeva ${ }^{1}$ \\ ${ }^{1}$ Kazan (Volga Region) Federal University, Kazan, Russia \\ Correspondence: Valeriy A. Letyaev, Kazan (Volga Region) Federal University, 420008, Kazan, Kremlyovskaya \\ Street, 18, Russia. E-mail: valeri.letyaev@gmail.com
}

Received: June 15, 2015 Accepted: June 24, 2015 Online Published: June 30, 2015

doi:10.5539/jsd.v8n7p159 URL: http://dx.doi.org/10.5539/jsd.v8n7p159

\begin{abstract}
The urgency of the research is determined by the fact that one of the major factors leading to corruption is ineffective and inadequate legislation that has corrupt signs. The objective of the article is to give a comprehensive examination of the theoretical issues arising in the sector of legal regulation and regulatory enforcement of anti-corruption expertise at the federal, regional and local levels. Foreign experience in the sphere has been taken into consideration. The leading research methods that allowed to perform a multi-method research were the Aristotelian, historical and genetic methods, the system analysis, and the comparative law. The paper presents the results of monitoring of the dynamics of the current legislation in anti-corruption expertise regulation sector as well as the gaps in legal regulation. There has been made a reasonable prospect for improving the current legislation on the basis of the current enforcement practices at the federal level and in the Republic of Tatarstan. The material of the article may be useful for legal practitioners, researchers in the fields of theory of law and state.
\end{abstract}

Keywords: anti-corruption expertise, propensity for corruption, theory of state and law.

\section{Introduction}

\subsection{Background}

In Russia constant increase in the number of regulatory legal acts (hereinafter - RLA) at different levels is accompanied by the emergence of legal defects: contradictions, repetitions, loopholes, etc. This fact weakens the integrity and efficiency of legal regulation and creates preconditions for the emergence of corruption, which, of course, worries Russian civil society. Therefore, one of the most important areas to which legislator's constant attention should be drawn remains the improvement of anti-corruption expertise of RLA aimed at eliminating corruption norms in them.

Review of scientific knowledge and regulatory enforcement presented in the article does not suggest that, over the last five years, the new laws proposed to improve the existing legislation in this sector have become law.

\subsection{Status of the Issue}

According to the results of the 2013 Global Corruption Barometer presented by the Transparency International movement, 114,270 people were surveyed in 107 countries. Speaking about Russia, the main conclusion made was that the population lost faith in the efficiency of the state anti-corruption campaign. Today, only $5 \%$ of the respondents consider the Government's efforts fighting corruption effective and no one has called them "very effective" (Transparency International Russia, 2013).

In recent years the scientific community has given particular attention to the issue of legal expertise especially after the adoption of relevant legislation both at the federal and at the lower levels of rulemaking. For example, the monitoring was based on 82 scientific papers, 9 monographs, 5 electronic resources including two comments to the legislation, and two textbooks.

The theoretical basis of the research were the works of N. Aleshkova (2012, 2013), V. Astanin (2009), K. Golovschinsky (2004), D. Gorokhov (2009), G. Egorov (2011), I. Efremov (2009), M. Krasnov (2004), K. Kudashkin (2012), V. Letyaev (2011), V. Syrykh (2002), E. Talapina (2004; 2007), Yu. Tikhomirov (2000), S. Filatov (2013, 2014), A. Filatova (2009), T. Khabrieva (2008; 2009), A. Tsirin (2009), V. Yuzhakov (2004, 2007) 
and other scientists who contributed to the study of the issues of anti-corruption expertise.

However, it should be noted that the low level of scientific novelty of the topic is explained by the novelty of the anti-corruption expertise institute.

Poor and imperfect legislative regulation of the anti-corruption expertise methodology is a promising stimulus for the creation of new criteria of propensity for corruption to be further included in regulations.

The main issues highlighted in scientific literature and requiring further investigation are the following:

1. An array of derivative bylaws (including the local ones) introducing unjustified variability in the sector of legal regulation of a regulatory legal act.

2. Insufficient quality of regulation.

3. Evaluation of regulatory legal acts for propensity for corruption is linked to significant investment of time, material and human resources.

4. There are some corrupt factors that are not formally included in the research methodology secured by the RF Government Decree.

5. Corruption goes beyond national boundaries.

6. Flaws of the Russian Federal Law "On Combating Corruption". A significant flaw of the law is lack of institutional consolidation of anti-corruption. The law does not create new structures; it does not give anyone the rights and obligations in this sector; it does not reform the existing institutions.

7. Autocratic judgment. The main legal issue dates back to its origin. It is the separation of methods of public and private law.

8. Corruption in the judicial system.

9. The issue of correct interpretation has always been and will be an urgent matter of law enforcement practice in public administration. Ambiguity, inaccuracy of the law leads to its arbitrary interpretation and, consequently, to arbitrary application.

10. A lot of studies raise the question of relationship of regulatory legal acts.

11. Researchers often do not examine the methodology and peculiarities of anti-corruption expertise but deal with the causes of corruption and point to the need to implement anti-corruption expertise.

12. Lack of specialists does not allow to carry out a qualitative anti-corruption expertise.

13. The issue of implementation of new powers in conducting anti-corruption expertise by prosecutors.

14. Issues of improving the techniques of production of anti-corruption expertise in the Russian Federation.

\subsection{Research Hypothesis}

Deterioration of the corruption rate in our country, understanding the extent of harmful effects of corruption on the prospects of economic, social and political development in the world as a whole have led to the recognition of the existence and significance of a particular problem in combating corruption - corruption issues of regulatory legal acts.

One of the most important factors contributing to corruption is substandard RLA the dictates of which are the foundation for corruption of officials and officers. Therefore, in Russia an important mechanism in the fight against corruption is the anti-corruption expertise of both the existing RLA and their projects.

Well-established procedures for conducting anti-corruption expertise of RLA create a stable regime to ensure high quality of the latter. This task cannot be achieved with the adoption of the set of derivative regulations (including local ones) introducing unjustified variability in the regulation of this sector.

At present, Russian law is facing a situation where anti-corruption expertise of regulatory legal acts is carried out without the RLA that establish new laws but take into account the experience of the previous years.

During the anti-corruption expertise it is important to establish the presence of the most typical corruption factors that contribute to the manifestation of corruption regulations and their projects as well as to determine the rules for their prevention and detection when preparing and adopting regulatory legal acts. Corruption factors may be consciously or inadvertently included in the text, comply with the rules of legal technique and break them (norm defects). These factors are divided into two main groups: the factors establishing an unreasonably wide margin of judgment for an executor of law or the possibility of unjustified use of exceptions to general rules; factors including unspecified, intractable and (or) onerous requirements for citizens and organizations. 
Examination of regulatory legal acts for corruption, as well as any other kind of activity, involves the use of a certain set (system) of methods and operations helping achieve the goal. In a broad sense, the purpose of examination of legal acts for corruption is to neutralize the corruption of a regulatory legal act. Examination of RPA for corruption should be carried out not only at the stage of RPA but also at the stage of their adoption as well as at the implementation phase according to the monitoring results of their application.

The process of anti-corruption expertise is based on the methods of normative analysis, functional analysis, and system analysis, statistical, sociological, and information methods, methods of expert rating and extrapolation.

Official anti-corruption expertise methodology was approved by the RF Government Decree of 26 February 2010 "On the anti-corruption expertise of legal acts and draft laws and regulations". It is necessary to improve the methodology of the anti-corruption expertise indicating therein examples that allow to see the actual use of corruption-factors for the extraction of corruption benefits (this provision has not been studied yet).

An effective mechanism to combat corruption is an anti-corruption monitoring of lawmaking and enforcement. On the one hand, monitoring is an integral part of improvement of legislation and law enforcement. On the other hand, it is an essential part of modern Russian state legal policy with anti-corruption policy as a component.

The analysis of scientific literature suggests the main pattern. The authors suggest improving the current legislation with the help of anti-corruption expertise which would eliminate the corruption-factors in the laws and their projects.

\section{Materials and Methods}

\subsection{Objectives of the Research}

The following objectives were put forth:

- to identify and present the dynamics of legal regulation of anti-corruption expertise in modern Russia.

- on the basis of monitoring of the current legislation in the sector of anti-corruption expertise of RLA to identify gaps in the regulatory framework.

- to develop and systematize current scientific knowledge about the conduct of anti-corruption expertise in Russia and its regions, for example, in Tatarstan, to identify scientific issues with the potential influence on the Russian legal anti-corruption policy.

- to identify and present a perspective experience of legal regulation of anti-corruption expertise of RLA in foreign countries.

- to identify and justify on the basis of theoretical analysis of scientific topics and law enforcement practice innovations for improving anti-corruption expertise of RLA.

To test the hypothesis general scientific methods common in the theory of law were used:

- formal and logical method of research which allowed using the basic rules of logic to tackle the objectives under study and achieve the aim of the study;

- historical and genetic method of research has allowed to analyze the emergence, formation and development of the concept of anti-corruption expertise in the Russian Federation;

- method of system analysis allowed to use system links analyzing the process of creation of high-quality rule of law;

- method of comparative legal analysis allowed to compare the functioning of the concept of anti-corruption expertise in Russia and other countries.

In addition, an important method that allowed to give a current complex study was the dialectical method of cognition.

The regulatory framework of research was made by the Federal Law of the Russian Federation of 17 July 2009 "On the anti-corruption expertise of legal acts and draft laws and regulations" as well as the standards of other legal acts regulating the procedure of carrying out anti-corruption expertise, including the most important of them - the Resolution of the Government of the Russian Federation of 26.02.2010 "On the anti-corruption expertise of legal acts and draft laws and regulations" and other normative acts at the federal and local levels.

The empirical base of the research includes the materials of the Russian representation of the Transparency International movement, the materials on the activities of the Legal Department of the State Council of the Republic of Tatarstan. 


\subsection{Stages of the Research}

The study was conducted in three stages:

The first part of the research dealt with the background of the concept of anti-corruption expertise in Russia, organizational and legal bases of its implementation. Methodology of conducting anti-corruption expertise in Russia and abroad was studied too.

The second stage studied the concept and signs of corruption of RLA and ways to resolve it.

The third stage identified and studied the problem of legal expertise existing in modern Russia and in the Republic of Tatarstan. There was made an overview of jurisprudence of the anti-corruption expertise.

\subsection{Evaluation Criteria}

The validity of the research results is based on the study of an array of regulations and scientific literature on the issue using the Consultant Plus reference system. The results were tested at the Department of Monitoring of Legislation and Anti-Corruption Expertise of the Legal Department of the State Council of the Republic of Tatarstan.

\section{Results}

Qualitatively established procedures of anti-corruption expertise of RLA create a stable regime to ensure its implementation. This task cannot be achieved with the adoption of a set of derivative regulations (including local ones) introducing unjustified variability in the regulation of this sphere. Variety of RLA really generates corruption because of contradictions between them.

In this regard, we propose to draft a federal law "On the procedure and methodology of anti-corruption expertise in the Russian Federation" specifying the powers and authority within it and stating the position specifications.

The federal law should indicate the phases of the expertise - from the starting point of the study of the RLA and up to the conclusion-making phase that will indicate the items to be included in the conclusion (in order to prevent free drafting).

The law must specify dates of the anti-corruption expertise, a mandatory list of sectors of legal regulation which should be subject to examination (public sector, tax, administrative, financial, etc.), the order of consideration of applications by individuals on specific regulations that they believe are corrupt. It should be noted that depending on the amount of RLA and its practical significance the terms will vary.

All existing corrupt factors that should be excluded from RLA and their projects must be specified.

It is also necessary to specify in the law a special body that will identify new corrupt factors taking into account international experience and peculiarities of the Russian legal system.

In Russia, at the legislative level new methods of examination are not applied and corrupt factors that were developed in 2004 have remained intact. Besides, at present the number of corrupt factors has reduced to 11 . All this means that the methodology of the anti-corruption expertise lags behind modern scientific knowledge and legal practice. Anti-corruption examination is carried out by authorized bodies within a strict framework, avoiding variability, and this significantly hinders identifying new corruption.

To solve the issues mentioned above we propose to amend the laws governing state and municipal service as the officers working in these sectors are one of the causes of corruption.

It is necessary to amend the existing legislation in the field of selection of state and municipal officers, to regularize quarterly reports of their activities to the public.

It is necessary to reform the judicial power and, in particular, to simplify the procedure of bringing judges to disciplinary responsibility, to reform the system of applying to qualified panel of judges with complaints about their illegal activities.

Legislative study of the existing anti-corruption legislation in order to identify its flaws and contradictions is also necessary, as the imperfect anti-corruption legislation may cause similar ineffective regulations. Therefore, we consider it necessary to agree with K. Strelnikov (2009) who criticizes the RF Federal Law "On Combating Corruption" justifying his position with examples. These deficiencies are quite possible to establish by amending the law.

Analytical review of the scientific literature has revealed that an effective mechanism to stop corruption is an anti-corruption monitoring of law-making and enforcement. On the one hand, monitoring is an integral part of improvement of legislation and law enforcement. On the other hand, it is an essential part of modern Russian 
state legal policy with anti-corruption policy as a component.

It has been proved that the examination of the RLA for corruption should be carried out not only at the stage of RLA but also at all stages of law-making as well as by the results of monitoring of their application.

\section{Discussions}

On the basis of the research there has been prepared an analytical review of the current scientific knowledge in the field of anti-corruption expertise which has not been carried out in such a scope before.

There has been elicited the main topic on anti-corruption expertise as well as a list of scholars who made a significant contribution to the study of the topic.

The issue of undue variability of legal regulation sector of the regulatory legal act was raised by T. Khabrieva (2009), I. Livshits (2008), S. Naryshkin (2008), and others. The issue of lack of legal regulation in connection with corruption standards was raised in the works of Yu. Tikhomirov (2007), S. Naumov (2009), N. Dorokhov (2006), A. Sokolov (2008), Yu. Buravlev (2008), A. Kozlov (2008), O. Zabolonkova (2009), M. Torkunov (2008), A. Kudashkin (2009), S. Bordin and N. Isaev (2014), A. Kurakin (2009), A. Nozdrachev (2007), and N. Shiryaev \& P. Zubkov (2008), M. Krasnov, E. Talapin, Yu. Tikhomirov, K. Golovschinsky \& V. Yuzhakov (2004), A. Tsirin (2009), and others. Examination of regulatory legal acts for corruption in terms of time, material and human resources was raised in the works of E. Savchenko (2008), A. Tsirin (2009), and V. Tentilov (2008). The problem of corrupt factors not included officially in the research methodology fixed by the Decree of the Russian Federation Government was raised for discussion by N. Lopashenko (2009). The fact that corruption goes beyond national borders was posed by V. Kozlov (2008). The shortcomings of the Federal Law of Russia "On Combating Corruption" in which there is no institutionalized anti-corruption activity were studied by K. Strelnikov (2009) and other scholars.

The topics of authoritative judgment were discussed in the works of E. Mishina (2009). The presence of corruption in the judicial system and its impact on systemic factors preventing corruption were considered by F. Shakhkeldov (2008). The issue of the relationship of legal acts in connection with the current research was raised in the works of D. Goncharov (2010). Issues of improving the techniques of production of anti-corruption expertise in the Russian Federation were raised by V. Kudryavtsev (2010) and other scholars. There has been defined and systematized legal regulation of anti-corruption expertise. The total number of RLA used in the research was 139 , including foreign ones.

Some judicial materials have been used. Authorized bodies face the problem of identifying corrupt standards. They sometimes cannot detect them at all. In this regard, we hope that the proposed position will help identify corrupt factors in regulatory legal acts and their projects that will allow to systematically and effectively address one of the most important state tasks - fight against corruption.

In particular, on May 19, 2010, considering case 3-22/10, the Supreme Court of the Republic of Tatarstan decided to invalidate paragraphs 7 and 10 of the Procedure for Harmonization of Calculation of Probable Harm Caused to the Life of Individuals and Property of Individuals and Legal Entities on the Territory of the Republic of Tatarstan in an Accident of the Hydraulic Structure (approved by the Cabinet of Ministers of the Republic of Tatarstan on 25.01.2010 by number 40).

On March 29, 2010, Leningrad Regional Court, considering case 3-26/2010 decided to invalidate paragraph 16 of the Regulations on Free Grant of Plots of Land as Property to Citizens for Individual Housing Construction in Leningrad region.

On December 10, 2009, the Central District Court of Novokuznetsk City made a decision on case 2-7469/09 which recognized invalid paragraphs 12 and 15 of appendix 1 to the Regulation of Land Tax in Novokuznetsk City approved by the Regulation of Novokuznetsk City Council of Deputies of 29.11.2006 by number 3/5.

There have been made suggestions, presented above in the results of the study, to improve the current legislation. These conclusions are debatable, and researchers are invited to discuss them.

\section{Conclusions}

The results of monitoring of the dynamics of the current legislation, law enforcement practices and scientific literature:

Qualitative procedures for conducting anti-corruption expertise of RLA create the basis of its stability. However, in the presence of a multiplicity of derivative regulations unjustified variation of regulation is created.

It is proposed to draft the federal law "On the Procedure and Methodology of Anti-Corruption Expertise in the 
Russian Federation" specifying the powers and authority within it and stating the position specifications. There should be indicated the phases of the expertise: from the moment when the RLA began to be studied and up to the moment when a conclusion indicating the items is made (it must be included in the conclusion in order to prevent free drafting). The law must specify dates of the anti-corruption expertise, a mandatory list of areas of legal regulation which should be subject to examination (public sector, tax, administrative, financial, etc.), the order of consideration of applications by individuals on specific regulations that they believe are corrupt. It should be noted that depending on the amount of RLA and its practical significance the terms will vary. All the existing corrupt factors must be specified that should be excluded from RLA and their projects. It is also necessary to specify in the law a special body that will deal with the identification of new corrupt factors taking into account global experience and peculiarities of the Russian legal system.

To solve the issues mentioned above we propose to amend the laws governing state and municipal service as the officers working in these sectors are one of the causes of corruption. We consider it absolutely essential to amend the existing legislation in the field of selection of state and municipal officers, to regularize quarterly reports of their activities to the public. It is also necessary to reform the judicial power, in particular, a simplified procedure of bringing judges to disciplinary responsibility, to reform the system of applying to qualified panel of judges with complaints about their illegal activities.

It has been found out that in Russia, statutorily, no new methods of examination are used and the corruption-factors that were developed in 2004 have still been intact. In addition, at present the number of corrupt factors has been reduced to 11. This fact implies that the methodology of the anti-corruption expertise lags behind modern scientific knowledge and practice. Anticorruption examination is carried out by authorized bodies within the strict framework, avoiding variability which significantly hinders reaching the goals of identifying new corruption.

The analytical review of the scientific literature suggests that an effective mechanism to combat corruption is an anti-corruption monitoring of lawmaking and enforcement. On the one hand, monitoring is an integral part of improvement of legislation and law enforcement. On the other hand, it is an essential part of modern Russian state legal policy with anti-corruption policy as a component.

It has been proved that the examination of RLA for corruption must be carried out not only at the stage of preparation of RLA but also at all the stages of lawmaking and in accordance with the results of monitoring of their application.

\section{Acknowledgments}

The work is performed according to the Russian Government Program of Competitive Growth of Kazan Federal University.

\section{References}

Aleshkova, N. P. (2012). Anti-Corruption Expertise of Draft Regulations as a Mandatory Part of Qualitative Lawmaking. Russian Justice, 10.

Aleshkova, N. P. (2013). Anti-Corruption Expertise of Regulatory Legal Acts: Current Issues and Possible soluTions. Municipal Law, 2.

Bordin, S. N., \& Isaev, N. S. (2014). Should the Commander Be Aware of Anti-Corruption Expertise? Right in the armed forces - military and legal review, 7.

Buravlev, Y. M. (2008). Corruption in the State Apparatus as a Systemic Phenomenon. Problems of Counteraction. Legal World, 12.

Dorokhov, N. I. (2006). Some Aspects of Assessment of Corruption as a Socio-Legal Phenomenon. Military Law Journal, 4.

Filatova, A. V. (2009). Examination of Regulations and Procedures of the Execution of Public Functions in the System of Expert Activity in Russia. Moscow: DMK Press,

Filatova, A. V. (2009). Policies and Procedures in the Implementation of State Control (Supervision). Saratov.

Goncharov, D. Yu. Relationship of Regulatory Legal Acts as the Principle of Anti-Corruption Expertise // Russian Justice. 2010. № 1. Access: SPS “Konsultant-Plus”.

Khabrieva, T. Ya. (2009). Formation of the Legal Basis of Anti-Corruption Expertise of Regulatory Legal Acts. Journal of Russian Law, 10.

Kozlov, A. V. (2008). Issue of Fighting Against Corruption in the Fiscal Sector. Taxes, 2. 
Krasnov, M. A., Talapina E. V., Tikhomirov, Yu. A., Golovschinsky, K. I., \& Yuzhakov, V. N. (2004). Analysis of corruption of Legislation: Expert's Memo on Primary Analysis of Corruption of Legislation. Moscow: The Statute.

Kudashkin, A. V. (2009). It is Time to Eliminate the Corruption Mechanism of Housing for Persons Discharged from Military Service (Anti-Corruption Expertise of Paragraph 1 of Article 23 of the Federal Law "On Status of Servicemen"). Right in the Armed Forces, 5.

Kudashkin, A. V. (2012). Anti-Corruption Expertise: Theory and Practice. Research and Practical Guide. Moscow: Norma, Infra-M.

Kudryavtsev, V. L. (2010). Some Issues of Improving the Methods of Production of Anti-Corruption Expertise in the Russian Federation. Forensics Analyst. 2.

Letyaev, V. A., \& Egorov, G. G. (2011). Corruption Threats in the Regulations of a Subject of the Federation. Volgograd: Volgograd Scientific Publishing.

Livshits, I. I. (2008). On Crime Rate of Russian Laws. Law and Economics, 4.

Lopashenko, N. A (2009). Corruption Factors: the Dangerous Transformation of Normative Interpretation. Legality, 10.

Mishina, E. A. (2009). Imperious Discretion: Good or Evil? Law and Economics, 11. Retrieved from http://www.smolgrad.ru/lawdigest/short/2201.htm

Naryshkin, S. E., \& Khabrieva, T. Yu. (2008). Administrative Reform in the Russian Regions. Journal of Russian Law, 10.

Naumov, S. Yu. (2009). Commentary to the Federal Law of 25.12.2008, № 272-FZ “On Combating Corruption”. Moscow: Yustitsinform.

Nozdrachyov, A. F. (2007). Corruption as a Legal Issue in Questions and Answers. Lawyer, 10.

Savchenko, E. J. (2008). Implementation of Anti-Corruption Mechanisms in the Activities of Executive Bodies of State Power of Subjects of the Russian Federation (at the example of Tambov region). Business Security, 1.

Shakhkeldov, F. G. (2008). Without Reforming the Judicial System Corruption Cannot Be Solved. Russian Judge, 12.

Shiryaeva, N., \& Zubkov, P. (2008). The Course towards a State of Law. Ezh-Lawyer, 5.

Sokolov, A. N. (2008). Corruption, Civil Society and a State of Law. Journal of Russian Law, 8.

Strelnikov, K. A. (2009). Issues of Implementation of the Federal law “On Combating Corruption”. Legal World, 3.

Syrykh, V. M. (2002). Sociology of Law. Moscow.

Talapina, E. V., \& Yuzhakov, V. N. (2007). Methodology of Primary Analysis (Examination) of Corruption of Regulatory Legal Acts. Moscow: The Statute.

Tenitilova, V. V. (2008). Criminological expertise as a Legal Instrument of Crime Prevention. Law and Education, 1.

Tikhomirov, Yu. A. (2000). Legislative technique. Moscow, 2000.

Tikhomirov, Yu. A. (2007). Enforcement: from Spontaneity to the System. Journal of Russian Law, 12.

Torkunov, M. A. (2008). Russian Legislation on Military Service Needs to be Improved (Military Jurisprudence). Right in the Armed Forces, 10.

Tsirin, A. M. (2009). Anti-Corruption Tools and Their Application in the Federal Bodies of Executive Power. Journal of Russian Law, 2.

Tsirin, A. M. (2009). Methodical Base of Assessment of Regulatory Legal Acts for Corruption. Journal of Russian Law, 10.

Zabolonkova, O. (2009). Anti-corruption measure: obligation to declare income. Power ministries and departments: accounting and taxation, 8.

\section{Copyrights}


Copyright for this article is retained by the author(s), with first publication rights granted to the journal.

This is an open-access article distributed under the terms and conditions of the Creative Commons Attribution license (http://creativecommons.org/licenses/by/3.0/). 